\title{
Atitudes étnico-raciais: elaboração e evidências de validade de uma medida do racismo à brasileira
}

\author{
Sheyla C. S. Fernandes ${ }^{1}$ \\ Marcos Emanoel Pereira ${ }^{2}$ \\ ${ }^{1}$ Universidade Federal de Alagoas, AL, Brasil \\ Dr ${ }^{a}$ em Psicologia Social https://orcid.org/0000-0003-4759-1314 \\ ${ }^{2}$ Universidade Federal da Bahia, BA, Brasil \\ Dr. Em Psicologia Social https://orcid.org/0000-0001-7613-689
}

\begin{abstract}
Resumo
O racismo brasileiro sobrevive em um contexto miscigenado e intercultural caracterizado por uma democracia racial aparente, fato que gera permanente necessidade de investigação. Este trabalho parte de dois interesses: 1) investigar alguns elementos do racismo no quadro das relações raciais brasileiras; 2) elaborar uma escala de atitudes étnico-raciais. Inicialmente, coletamos as crenças sobre as pessoas negras e sobre as relações raciais junto a 678 universitários de cinco estados do Brasil. Em seguida, tomando como base os resultados da primeira fase, elaboramos e aplicamos a uma amostra de 195 universitários o modelo experimental da escala de atitudes étnico-raciais (EAER). Uma análise dos componentes principais indicou a existência de dois fatores com índices de confiabilidade interna satisfatórios, atitudes sobre a existência do racismo, com elevada adesão dos estudantes, e atitudes frente às diferenças entre negros e brancos, com baixa adesão. A EAER demonstra ser um instrumento apto às configurações do racismo brasileiro e útil para futuras investigações.
\end{abstract}

Palavras-chave: Racismo; Escala; Relações raciais.

\section{Ethnic-racial attitudes: elaboration and evidence of validity of a measure of brazilian racism}

\begin{abstract}
Brazilian racism survives in a mixed and intercultural context characterized by an apparent racial democracy, a fact that generates a permanent need for investigation. This work is based on two interests: (1) to investigate some elements of racism within the framework of Brazilian racial relations; (2) elaborate a scale of ethnic-racial attitudes. Initially, we collected the beliefs about blacks and racial relations among 678 university students from five Brazilian states. Then, based on the results of the first stage, we elaborated and applied to a sample of 195 university students the experimental model of the ethnic-racial attitudes scale (EAER). An analysis of the principal components indicated the existence of two factors with satisfactory internal reliability indexes, attitudes about the existence of racism, with high students' adherence, and attitudes toward the differences between blacks and whites, with low adherence. The EAER demonstrates to be an instrument apt to the configurations of Brazilian racism and useful for future researches.
\end{abstract}

Keywords: Racism; Scale; Racial relations. 


\title{
Escala de atitudes étnico-raciales: elaboración y evidencias de validez de una medida del racismo brasileño
}

\begin{abstract}
Resumen
El racismo brasileño sobrevive en un contexto mixto e intercultural caracterizado por una democracia racial aparente, hecho que genera una permanente necesidad de investigación. Este artículo presenta dos problemas: (1) investigar algunos elementos del racismo en el marco de las relaciones raciales brasileñas; (2) elaborar una escala de actitudes étnico-raciales. Inicialmente, colectamos las creencias sobre los negros / relaciones raciales junto a 678 universitarios de cinco estados de Brasil. A continuación, tomando como base los resultados de la primera fase, elaboramos y aplicamos a una muestra de 195 universitarios el modelo experimental de la escala de actitudes étnico-raciales (EAER). Un análisis de los componentes principales indicó la existencia de dos factores con índices de confiabilidad interna satisfactorios, actitudes sobre la existencia del racismo, con elevada adhesión de los estudiantes, y actitudes frente a las diferencias entre negros y blancos, con baja adhesión. La EAER demuestra ser un instrumento apto para las configuraciones del racismo brasileño y útil para futuras investigaciones.

Palabras clave: Racismo; Escala; Relaciones raciales.
\end{abstract}

\section{Introdução}

Com base no argumento de que as relações raciais em países onde a segregação não ocorre tanto pelo viés das diferenças culturais, como é o caso do Brasil, foi desenvolvido o termo racismo cordial para se referir a uma modalidade peculiar de racismo ou racismo à brasileira (Pacheco, 2011). Este tipo de racismo foi detectado em um estudo encomendado pelo Datafolha na década de 1990, cujo objetivo consistiu em analisar as relações raciais brasileiras (Turra \& Venturi, 1995). Os autores aplicaram uma série de questionários com perguntas diretas e indiretas sobre o racismo. Os dados demonstraram que apenas $10 \%$ dos brasileiros investigados se consideram racistas; no entanto, um número superior a $50 \%$ de respondentes concordam com frases do tipo "Negro bom é negro de alma branca" ou "Negro quando não faz besteira na entrada, faz na saída", ou ainda, "Se Deus fez raças diferentes, é para que elas não se misturem". Turra e Venturi (1995) denominaram de "racismo cordial" o tipo de racismo que ocorre no Brasil em virtude da cordialidade com que se nega ser racista, em um país onde, na própria opinião dos participantes do estudo citado, o racismo é notório. De acordo com os autores, a grande maioria dos entrevistados demonstrou ter ou estar propensa a apresentar preconceito em relação à pessoas negras, mas quis minimizar seu impacto, $\mathrm{o}$ que indica uma demonstração de cordialidade - talvez, para não ofender ainda mais aquele que se discrimina (Turra \& Venturi, 1995).

Estudos posteriores buscaram analisar este padrão de racismo (Camino et al., 2004; Camino et al., 2014; Nicolau \& Müller, 2017), apresentando definições que remetem o racismo cordial ao nível das relações interpessoais, pautado, sobretudo, em formas indiretas de expressar a antipatia contra negros e/ou pessoas não brancas. Tal expressão é caracterizada por camuflar atitudes e comportamentos excludentes, expressos nas relações cotidianas através de piadas, ditos populares e brincadeiras de cunho racial.

Neste sentido, em um nível ideológico, Camino et al. (2004) demonstraram que o preconceito racial é mais facilmente expresso quando faz parte dos repertórios dos outros, ao passo que quando o preconceito é referido a si, os participantes tendem a negar sua existência. Os dados desta pesquisa sugerem que as pessoas utilizam um duplo padrão de avaliação do preconceito racial, um padrão que é dimensionado ao discurso ideológico dos brasileiros em geral e um padrão dimensionado ao próprio discurso, como se os discursos pessoais não possuíssem relação com o discurso ideológico da nação da qual fazem parte. Contudo, os autores da pesquisa destacam que esta duplicidade não deve ser entendida como 
resultante de um conflito psicológico, pois claramente reflete o discurso ambíguo já detectado no Brasil quanto às questões étnicas e raciais. Além dessa ambiguidade, o discurso das autopercepções de preconceito racial e da percepção da sociedade brasileira apresentam dados bastante semelhantes, que diferem especialmente quanto à magnitude de discurso preconceituoso apresentado, mas que nos padrões semânticos são muito próximos. Para descreverem os negros, os participantes utilizaram adjetivos mais de pessoas do terceiro mundo (aptidões menos qualificadas, inatas, ligadas ao esporte ou à arte) do que de pessoas do primeiro mundo (aptidões mais qualificadas, ligadas a atividades intelectuais ou ao poder), tanto em relação à opinião pessoal quanto em relação à opinião dos brasileiros em geral, da mesma forma que para descreverem pessoas brancas utilizaram mais adjetivos de pessoas do primeiro mundo do que do terceiro mundo, divergindo em todos os casos na magnitude dessas respostas. Esses dados indicam que, tanto no nível ideológico quanto no nível operacional, o preconceito racial existe e de maneira complexa em uma sociedade miscigenada, cujos atores sociais compartilham, dentre outras características, a mesma cultura (ver Camino et al., 2014; Lins et al., 2014).

Com efeito, no Brasil, a catalogação de cores indicadas por meio da autocategorização chega a 135 formas distintas (Turra \& Venturi, 1995), isso somado ao contato inter-racial se constitui como um dos fenômenos seminais da identidade e cultura brasileiras. Esses elementos associados a demais questões culturais e históricas (como o mito da democracia racial e a ideologia do branqueamento), fazem emergir neste país essa forma específica de expressão do racismo (Lima \& Vala, 2004), que se distancia das demais formas dos novos racismos e preconceitos na medida em que um dos seus principais fatores consiste justo no compartilhamento cultural e não na ameaça dos valores tradicionais ou da mudança cultural do grupo majoritário. Esses diversos tipos de preconceito e racismo suscitaram um vasto campo de investigação cuja mola propulsora consiste em desvendar a natureza e manutenção desses fenômenos.
Em uma análise teórica e metodológica do preconceito e do racismo, Lima (2003) apresenta que a maior parte dos estudos na área da psicologia social organiza as estratégias de investigação do preconceito e do racismo em três gerações. A primeira geração utiliza medidas abertas (ex.: escala de distância social de Bogardus, na década de 1920, ou a escala de estereótipos de Katz \& Brally, na década de 1930), caracterizadas por avaliar os níveis explícitos de preconceito. Nesse cenário, com a ausência de comprovações da teoria das raças, que previa diferenças concretas entre brancos e negros, e a ocorrência de eventos históricos (Primeira Guerra Mundial; movimento pelos direitos civis dos negros, em 1920, nos Estados Unidos; os movimentos que questionavam a legitimidade da supremacia branca na Europa), ocorre a germinação de novos estudos sobre as relações raciais (Lins et al., 2014; Guimarães, 2016). O conceito de raça baseado em características genotípicas exclusivamente, foi substituído progressivamente pelo conceito de grupo étnico, apoiado em diferenças culturais e comportamentais (Cabecinhas \& Amâncio, 2003). Nesse período, os estudos analisavam as atitudes raciais das pessoas brancas, uma vez que o preconceito parecia ser uma atitude injustificada. Inicia-se a utilização das escalas de distância social e os estudos sobre estereótipos por meio das escalas de Thurstone e Likert em estudos inter-raciais de atitudes. Esses estudos apresentaram resultados alarmantes, identificando o alto nível de preconceito racial e de distância social entre grupos tidos como majoritários e minoritários (Bogardus, 1928 como citado em Cabecinhas, 2004).

A segunda geração, que teve início na década de 1960, é caracterizada por medir formas mais sutis de preconceito por meio de medidas indiretas, posto que apresentavam questões menos reativas e incisivas. Nessa perspectiva, a pressão social a favor das normas igualitárias tornou as medidas explícitas de racismo inconsistentes, uma vez que as pessoas passaram a camuflar suas atitudes raciais. Exemplos dessas medidas são as escalas de preconceito moderno de McConahay 
(1986), de preconceito sutil de Pettigrew e Meertens (1995), que analisam os indicadores do preconceito indireto através de determinantes de ordem cultural ou da ameaça percebida de despadronização dos valores do grupo dominante. Podem também ser inseridas nesse domínio as medidas de essencialismo e infra-humanização que utilizam a atribuição diferenciada de traços e de emoções ao exogrupo, colocando-o em posição de desvantagem (Leyens \& Vala, 2016; Pereira et al., 2009).

$\mathrm{Na}$ última geração de medidas do preconceito e do racismo, os procedimentos utilizados se referem à análises das atitudes raciais inconscientes ou automáticas (Devine, 1989; Lai et al., 2014). A proposta desse nível de medida é analisar o preconceito de modo que o indivíduo não tenha controle consciente sobre sua resposta. Oslon e Fazio (2006) definem que esse tipo de medida proporciona uma estimativa acerca da avaliação que as pessoas fazem em relação a um alvo (ex.: negros e brancos, podendo-se utilizar quaisquer grupos) através da facilidade com que associam certos atributos a ele. A ativação automática de estereótipos e preconceito vem sendo investigada na psicologia em um amplo número de estudos que se concentram em dois paradigmas dominantes: a latência de resposta e o priming (Lima et al., 2006; Lupker et al., 2015).

As três gerações de medidas do preconceito e do racismo podem ser estruturadas também em função do tipo de resposta que cada uma avalia: medidas diretas e medidas indiretas (Olson, 2009). As medidas diretas são definidas como aquelas que solicitam dos participantes respostas verbais acerca de suas atitudes, logo, respostas conscientes e controladas (ex.: escalas de atitudes raciais); e as medidas indiretas são definidas como aquelas que não requerem expressões verbais, são automáticas e, portanto, incontroladas (ex.: medida de priming). Este autor enfatiza que o último conjunto de medidas está em abundante uso atualmente, mas refere que muito se tem a esclarecer sobre os mecanismos subjacentes e sobre a natureza dos construtos que as medidas indiretas avaliam.

Para Allport (1954), um dos primeiros teóricos a abordar os aspectos teórico-metodológicos do pre- conceito, a utilização de perspectivas ou enfoques distintos sobre o preconceito possui um caráter mais complementar do que divergente, ponto que beneficia o estudo deste construto, uma vez que em conjunto, diferentes perspectivas podem suscitar uma análise mais abrangente e completa do preconceito.

As denominadas teorias das novas formas de racismo ou preconceito se configuram como uma nova tendência no estudo do preconceito, que se diferencia das formas mais tradicionais na medida em que, teoricamente, aplicam ao conceito deste fenômeno tanto um novo olhar, como, metodologicamente, utilizam uma maneira distinta de abordá-lo. O conceito de preconceito passa a ser vinculado estreitamente às normas sociais e com isso, analisado em função destas, e por conta dessa relação, a expressão que em um modelo mais tradicional se dava de forma explícita, passa a ser mascarada, dado que exigiu dos teóricos a confecção de novas estratégias de medida (Kite \& Whitley, 2016). Seja o modelo do "novo racismo sob-a-pele" (a new under-the-skin racism) na França, "preconceito latente" (latent prejudice), na Alemanha, "novo racismo" (new racism), na Inglaterra, "racismo cotidiano" (everyday racism), na Holanda, "racismo simbólico" (symbolic racism), "racismo moderno" (modern racism), "racismo aversivo" (aversive racism) e "racismo ambivalente" (ambivalent racism), nos Estados Unidos, todos guardam em comum o interesse em avaliar essas novas configurações do preconceito e racismo (ver Pettigrew \& Meertens, 1995).

Neste sentido, esforços contínuos de elaboração de novos instrumentos capazes de mensurar atitudes raciais vêm sendo realizados internacionalmente (Oswald et al., 2013). Contudo, no Brasil os estudos realizados geralmente se detêm a adaptações e validações de escalas, em grande parte, norte-americanas (Fattore et al., 2016; Costa-Lopes et al., 2008; Santos et al., 2006). Tendo em vista a necessidade de avançar no conhecimento sobre as novas configurações do preconceito racial no contexto brasileiro, o presente artigo tem como objetivos analisar as atitudes em relação às pessoas negras e às relações raciais 
e elaborar uma escala capaz de medir essas atitudes. Para tanto, o estudo foi desenvolvido em duas etapas.

\section{Etapa 1 - Método}

\section{Participantes}

Participaram do estudo 678 estudantes universitários, sendo a maioria do gênero feminino $(71,5 \%)$, solteiros $(81 \%)$ e católicos $(71,3 \%)$, com idades entre 18 e 64 anos $(M=24,7 ; \mathrm{DP}=8,19)$. De cinco estados brasileiros, Bahia (15,3\%), Goiás (11,9\%), Pará (14\%), Rio Grande do Sul $(27,9 \%)$ e Sergipe $(30,8)$.

\section{Instrumentos e procedimentos}

Para coletar os dados junto aos estudantes, após o preenchimento voluntário do Termo de Consentimento Livre e Esclarecido (TCLE), foi utilizado um livreto que, além de um conjunto de questões sociodemográficas, solicitava aos participantes que respondessem abertamente que sentimentos, pensamentos ou imagens surgem à mente a partir da palavra "negros".

Para analisar as respostas obtidas, foi utilizado o Alceste (Reinert, 1998), um software que permite realizar análise de conteúdo por meio de técnicas quali-quantitativas e se propõe a identificar o sentido essencial de um texto (Pombo-de-Barros, 2011). Uma das primeiras operações realizadas é a fragmentação inicial que constitui a Unidade de Contexto Inicial (UCI); em seguida, é efetuado o trabalho de classificação para estabelecer as matrizes de pertencimento das palavras, a Unidade de Contexto Elementar (UCE); posteriormente ocorre o agrupamento de UCE sucessivas dentro de uma mesma UCI. As UC (Unidade de Contexto) devem ter estabilidade semântica e tamanho compatível, pois estão na base de todas as estatísticas efetuadas. A 'Classe', refere o agrupamento constituído por várias UCE de vocábulo homogêneo. A lematização, por sua vez, visa a substituição de certas palavras por uma forma reduzida, que permite ao programa considerar a equivalência de palavras com radicais comuns. A
AFC (Análise Fatorial de Correspondência), por fim, é a operação de cruzamento entre o vocábulo e as classes (Nascimento \& Menandro, 2006).

\section{Análise dos dados}

Nessa fase buscamos analisar os conteúdos referentes às crenças sobre a categoria social "negros" objetivando traçar um mapeamento que permitisse o conhecimento das crenças sobre os negros e sobre as relações raciais para, na sequência, elaborar uma escala sobre atitudes em relação às pessoas negras e às relações raciais.

Para realização da análise de conteúdo informatizada com a utilização do Alceste, inicialmente foram selecionados de forma aleatória 285 questionários, sendo 50 da cidade de Aracaju, 35 da cidade de São Paulo, 50 da cidade de Salvador, 50 da cidade de Belém, 50 da cidade de Goiânia e 50 da cidade de Porto Alegre.

\section{Resultados}

O corpus foi constituído por 285 respostas, ou seja, Unidades de Contexto Inicial (UCI). A partir deste corpus foi encontrada uma divisão em 222 Unidades de Contexto Elementar (UCE), correspondendo a 65,88\% do total, o que indica que $34.12 \%$ do corpus foram descartados das análises por não atenderem aos critérios estatísticos [ $\chi 2(1) \geq 3,84, p<0,05]$. Em linhas gerais, este dado indica que quanto maior for a porcentagem de texto analisado, melhor será a análise. Não há exatamente um ponto de corte para avaliação de uma boa ou uma incipiente análise de conteúdo (Reinert, 1998), essa escolha fica a critério do pesquisador diante de sua análise semântica (Alba, 2004). De fato, os dados apresentaram uma UCE superior a metade do corpus, o que nos permite avaliar como satisfatória, tendo em vista, sobretudo, que todas as demais análises são realizadas a partir das UCE selecionadas, em outras palavras, as UCE que representam a tipicidade de respostas do grupo.

Duas classes emergiram do corpus, a estas classes atribuímos títulos funcionais no sentido de descrevê-las: 1) atributos histórico-morais relativos às pessoas negras 
e 2) atributos físicos ou fenotípicos relativos às pessoas negras (Tabela 1).

Tabela 1. UCE predominante das classes

\begin{tabular}{|c|c|}
\hline \multicolumn{2}{|r|}{ Unidade de Contexto Elementar } \\
\hline \multicolumn{2}{|r|}{$\begin{array}{c}\text { CLASSE } 1 \\
\text { (atributos histórico-morais relativos às pessoas negras) }\end{array}$} \\
\hline \multicolumn{2}{|l|}{$\mathrm{X}^{2}$} \\
\hline 9 & Raça forte, mas sofrida quanto à marginalidade, gente lutadora. \\
\hline 8 & $\begin{array}{l}\text { Preconceito, racismo que parte tanto dos brancos como dos } \\
\text { negros. }\end{array}$ \\
\hline 7 & Desigualdade social e preconceito. \\
\hline 7 & Luta, força, sofrimento. \\
\hline 7 & Persistem apesar dos obstáculos sociais, econômicos e culturais. \\
\hline 7 & Luta, sofrimento, força, coragem. \\
\hline 7 & Gente sofrida, suprimidos pelo preconceito, homens agressivos. \\
\hline 7 & Escravidão, discriminação e racismo. \\
\hline 7 & Desigualdade moral e social, crianças desnutridas na África. \\
\hline 7 & Cultura, luta, África, Brasil. \\
\hline 7 & Raça que historicamente tem muitas desigualdades sociais. \\
\hline 5 & Penso em escravos, mas faço parte dos negros. \\
\hline 4 & Escravos, pobres, sentimento de culpa pelo desigual. \\
\hline 4 & Preconceito, não concordo que eles sejam chamados de negros (...) \\
\hline 4 & Imagens fortes de pessoas fora dos padrões estéticos (...) \\
\hline 4 & Respeito, cotas, África, escravos, quebra de preconceito. \\
\hline 4 & Desigualdade, rejeição, preconceito. \\
\hline \multirow[t]{2}{*}{4} & Muitas vezes com negros artistas e criadores de cultura. \\
\hline & Unidade de Contexto Elementar \\
\hline \multicolumn{2}{|r|}{$\begin{array}{c}\text { CLASSE } 2 \\
\text { (traços físicos ou fenotípicos relacionados às pessoas negras) }\end{array}$} \\
\hline 5 & Uma pessoa de pele escura apenas. \\
\hline 5 & Pessoas normais que apenas tem uma outra cor. \\
\hline
\end{tabular}

\begin{tabular}{|l|l|}
\hline 5 & Uma pessoa de pele negra. \\
\hline 5 & Normal, pessoas de pele negra. \\
\hline 5 & Uma pessoa comum, igual a mim e aos outros. \\
\hline 5 & São iguais a todos, não vejo diferença de pele e sim de caráter. \\
\hline 5 & A cor negra, pessoas de pele negra. \\
\hline 5 & Seres humanos como outro qualquer. Pessoas de pele escura. \\
\hline 5 & Pessoas iguais de pele escura. \\
\hline 5 & Pessoas de pele escura, uma variedade de nossa espécie. \\
\hline 5 & Uma pessoa normal, comum igual a todos. \\
\hline 5 & Uma pessoa de pele escura com um sorriso no rosto. \\
\hline 3 & Uma pessoa de pele escura. \\
\hline 3 & Pessoa de pele escura. \\
\hline 3 & Pessoa de pele escura. \\
\hline 3 & Pessoas de cores diferentes, mas com a mesma capacidade. \\
\hline 3 & Uma pessoa normal. \\
\hline 3 & Pessoa de pele escura. \\
\hline
\end{tabular}

A primeira classe, constituída por 81 das 222 UCE explicam $36,49 \%$ do total, organizou evocações que referem traços originários da trajetória histórica dos negros, além de traços relacionados diretamente a sua cultura e emoções morais (normativas) dos respondentes em relação à cultura dos negros (ex.: "Raça forte, mas sofrida quanto à marginalidade, gente lutadora"; "Desigualdade social e preconceito"; "Raça que historicamente tem muitas desigualdades sociais"). No que se refere ao indicador de atributos morais, os resultados demonstraram que os participantes representam a categoria social "negros" por meio de julgamentos de valor "polidos" associados à raça negra, dito de outro modo, os participantes referem-se a princípios morais que norteiam seus pontos de vista em relação a essa raça (ex. "Sentimento de culpa pela desigualdade"; "Não concordo que sejam chamados de negros"; "Respeito, quebra de preconceitos"). Esse 
tipo de repertório é observado corriqueiramente em investigações sobre preconceito racial e racismo. Cada vez mais está presente a preocupação em expor formas menos abertas de discriminação que, embora expressas, não infringem a norma social de indesejabilidade do racismo (Lins et al., 2014; Camino et al., 2013).

A segunda classe foi constituída por evocações que se referem às características da aparência física, logo, características herdadas, imutáveis e salientes (ex.: "Uma pessoa de pele mais escura apenas"; "Pessoas normais com apenas uma outra cor"; "Pessoas com a pele escura, uma variedade de nossa espécie").

Observa-se que a segunda classe, mais que a primeira apresentou um conjunto de UCE claramente semelhante, ou seja, as UCE da segunda classe (traços físicos ou fenotípicos) de forma sistemática agregaram unidades indicativas da cor da pele dos negros, não sendo incorporada nenhuma variação de outro traço físico, como cabelo, nariz, força física, comumente encontrados em outros estudos sobre representações da raça negra (Batista et al., 2014; Máximo et al., 2012).

As UCE de ambas as classes foram utilizadas para elaboração inicial de uma escala capaz de analisar atitudes em relação às pessoas negras e às relações raciais. As definições clássicas de preconceito e preconceito étnico de Allport (1962) guiaram as considerações levantadas pelos resultados. Allport define o preconceito como: "Uma atitude hostil ou antecipada em relação a uma pessoa que pertence a um grupo, simplesmente porque pertence a esse grupo, supondo-se portanto, que possui as qualidades objetais atribuídas ao grupo" (Allport, 1962, p. 22). Nesse sentido, o preconceito consiste em uma atitude negativa, e sendo relacionado à etnia, é definido como "uma antipatia que se apoia em uma generalização errada e inflexível. Pode sentir-se ou expressar-se. Pode estar dirigida a um grupo em geral, ou a um indivíduo por ser membro do grupo" (Allport, 1962, p. 24). Assim, a escala de medida desenvolvida nesta etapa da pesquisa foi denominada de Escala de Atitudes Étnico-Raciais (EAER).
Efetuamos alguns ajustes de modo que as unidades pudessem se configurar em itens representativos das evocações e especificamente das classes. Além disso, incluímos algumas sentenças que se referem às crenças sobre os negros, adaptadas do estudo de Turra e Venturi (1995). Na sequência, considerando o conjunto diversificado de itens elaborados representantes das duas classes, agrupamos estes em cinco fatores: 1) atributos fenotípicos; 2) atributos psicológicos; 3) atributos histórico-culturais; 4) emoções morais frente o preconceito e 5) percepção da existência do preconceito.

Nessa oportunidade, realizamos a análise de juízes. Contamos com a participação de sete juízes especialistas no tema abordado. Essa análise teve por fim estabelecer a compreensão teórica dos itens e a sua adequação ao construto que visa medir. Permaneceram os itens que apresentaram uma concordância de pelo menos $80 \%$ entre os juízes. Em seguida, foi verificada a sua validade semântica por meio da análise com o estrato mais baixo da população a que se destina. Nesse caso, contamos com a participação de doze estudantes de ambos os gêneros, de primeiro período do curso de Psicologia. Por fim, após esta avaliação, as modificações indicadas foram realizadas e a versão experimental da EAER foi submetida a teste.

\section{Etapa 2 - Método}

\section{Participantes}

Participaram do estudo 195 estudantes universitários do curso de Psicologia de duas universidades da cidade de Maceió (AL), sendo a maioria do gênero feminino (54,6\%) com idades entre 18 e 32 anos (média $=20,67$; $\mathrm{DP}=2,72)$ que cursavam até o terceiro período $(73,6 \%)$.

\section{Instrumentos e procedimentos}

Foi utilizado um questionário que, além de dados sociodemográficos (como gênero, idade, curso etc.) requeria dos participantes o preenchimento do modelo experimental da EAER. Essa escala foi composta por 44 itens representantes das crenças raciais distribuídas em 
cinco dimensões (elaborados a partir da análise anterior): 1) atributos fenotípicos (ex.: "A beleza das pessoas negras é diferente (exótica).”; "A cor da pele é a única coisa que diferencia negros e brancos."); 2) atributos psicológicos (ex.: "O que diferencia os negros dos brancos é o caráter."; Percebo que os negros se diferenciam dos demais em termos de capacidade"); 3) atributos histórico-culturais (ex.: "A escravidão é a marca central da raça negra."; "Penso que as pessoas negras encontram obstáculos socioeconômicos e culturais.”); () emoções morais frente ao preconceito (ex.: "Sinto raiva ao ver uma pessoa negra sendo discriminada"; Não me sinto à vontade para falar de preconceito com uma pessoa negra"); e 5) percepção da existência do preconceito (ex.: "Eu penso que os negros são marginalizados"; "Em minha opinião os negros sofrem discriminação"), conforme exposto anteriormente. Utilizamos uma escala de respostas tipo likert de cinco pontos, variando de 1 (discordo totalmente) a 5 (concordo totalmente).

Os participantes responderam ao instrumento individualmente, mas em situação de sala de aula. Previamente contatávamos o professor responsável pela turma no momento da coleta e, após sua autorização, contávamos os participantes que desejavam participar da pesquisa. Esses recebiam as informações sobre a pesquisa e sobre a garantia das diretrizes éticas para pesquisa com seres humanos. Em seguida, os participantes preenchiam o termo de consentimento livre e esclarecido e tomavam parte na pesquisa. Em média os participantes levavam 20 minutos para o preenchimento do questionário.

\section{Análise dos dados}

Objetivando analisar o modelo experimental da EAER, realizamos análises fatoriais exploratórias e análises da confiabilidade interna dos fatores indicados pela análise fatorial. Utilizamos a versão 22.0 do SPSSPW.

\section{Resultados}

Inicialmente testamos os índices estatísticos da matriz de correlações dos itens da escala através do teste de
KMO (Kaiser-Meyer-Olkin) e do teste de esfericidade de Bartlett (medidas que analisam a adequação dos dados para serem submetidos a uma análise fatorial). Encontramos resultados satisfatórios $(\mathrm{KMO}=0,69$; $\left.X^{2}(946)=2348,196 ; p=0,000\right)$. Realizamos então uma análise fatorial dos componentes principais, com rotação varimax, sem especificar o número de fatores. Obtivemos uma estrutura composta por 13 fatores, o que nos evidenciou a necessidade de utilizar o diagrama de declividade (screeplot) como critério para avaliar a dimensionalidade do construto (ver Field, 2009; Damásio, 2012) (Figura 1).

Figura 1: Diagrama de declividade da EAER

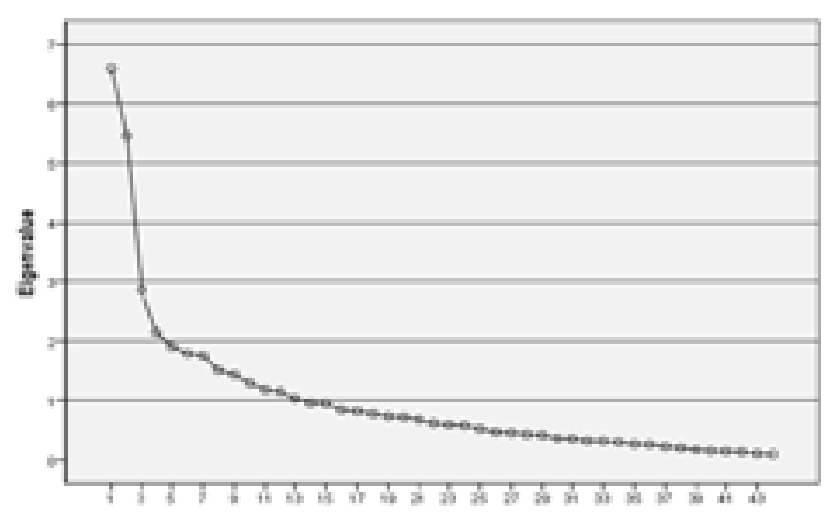

O diagrama de declividade pode ser adotado para estabelecer a quantidade mais adequada de fatores extraídos da matriz de correlações (Dancey \& Reidy, 2013). A ideia é que os fatores decresçam até certo nível e depois formem uma linha quase horizontal, sendo a regra incluir todos os valores que estiverem anteriores a esse ponto. Como podemos observar no diagrama, poderíamos assumir uma estrutura composta por até três fatores. Não obstante, o resultado da análise fatorial disposta em três fatores apresentou dois fatores nitidamente preponderantes, um pertinente às crenças sobre a existência do preconceito racial e um segundo pertinente a junção das crenças sobre os traços naturais fenotípicos e psicológicos, e um terceiro fator ambíguo onde foram acoplados os itens pertinentes tanto ao que seriam as crenças sobre os traços histórico-culturais e sobre as emoções morais frente ao preconceito (Tabela 2). 
Tabela 2. Análise dos Componentes Principais da EAER em 3 fatores

\begin{tabular}{|c|c|c|c|}
\hline \multirow{2}{*}{ Itens } & \multicolumn{3}{|c|}{ Fatores } \\
\hline & 1 & 2 & 3 \\
\hline 37 - As pessoas negras sofrem preconceito. &, 773 & & \\
\hline 40 - Os negros sofrem discriminação. & ,767 & & \\
\hline 41 - A sociedade discrimina as pessoas negras. & ,732 & & \\
\hline 28 - Os negros sofrem com as injustiças sociais. & ,709 & & \\
\hline 36 - Os negros são marginalizados pela sociedade. & ,705 & & \\
\hline 23 - As pessoas negras encontram obstáculos sócio-econômicos e culturais. &, 643 & & \\
\hline 13 - Os negros são marginalizados. &, 507 & & \\
\hline 38 - O racismo parte tanto dos brancos como dos próprios negros. &, 442 &,- 339 & \\
\hline 18 - Os negros têm preconceito contra eles mesmos. & ,417 & & \\
\hline 35 - A raça negra está associada à desigualdade social. & 364 & 335 & \\
\hline 2 - As pessoas negras têm mais dificuldade na vida do que outras pessoas. & 349 & & \\
\hline 24 - Os negros se diferenciam dos demais em termos de capacidade. & & ,744 & \\
\hline 20 - O que diferencia os negros dos brancos é o caráter. & & ,743 & \\
\hline 29 - O que diferencia os negros dos demais é a capacidade intelectual. & & ,740 & \\
\hline 43 - Por conta da escravidão os negros não atingem sucesso na vida. & & ,636 & \\
\hline 17 - Os negros são pessoas comuns, iguais a mim e aos outros. &,- 449 & 622 & \\
\hline 19 - Os negros são tão inteligentes quanto os brancos. & &, 572 & \\
\hline 15 - Os negros são iguais a todos em termos de capacidade. &,- 481 &, 557 & \\
\hline 34 - O preconceito é uma invenção de revolucionários negros. & ,306 &,- 440 & \\
\hline 10 - Apesar dos obstáculos, os negros estão alcançando um lugar melhor na sociedade. & &,- 420 & \\
\hline 22 - A raça negra está ligada à escravidão. & & ,409 & \\
\hline 25 - A cultura dos negros é marginalizada. &, 323 &, 340 & \\
\hline \multicolumn{4}{|l|}{33 - Os negros de classe social alta não são discriminados pela sociedade. } \\
\hline \multicolumn{4}{|l|}{42 - O preconceito só existe quando o negro é pobre. } \\
\hline \multicolumn{4}{|l|}{3 - A cor da pele é a única coisa que diferencia negros e brancos. } \\
\hline \multicolumn{4}{|l|}{11 - Os negros constituem uma das variedades da espécie humana. } \\
\hline 26 - Os negros alcançam melhores resultados no esporte. & & &, 690 \\
\hline 27 - A raça negra é uma raça forte e persistente. & & & 671 \\
\hline 9 - Os negros são melhores na dança. & & & 659 \\
\hline 21 - Os negros são corajosos. & & &, 539 \\
\hline 16 - A cultura dos negros é diferente. & & &, 531 \\
\hline 30 - A escravidão é a marca central da raça negra. & & & 481 \\
\hline 8 - A cultura negra tem uma beleza diferente. & & &, 477 \\
\hline 39 - A humildade é uma característica marcante na personalidade dos negros. & & & 455 \\
\hline 7 - Os negros possuem maior força física quando comparados com os brancos. & & &, 434 \\
\hline 44 - Os traços físicos dos negros são marcantes. & & & 410 \\
\hline 32 - Os negros possuem a sexualidade aguçada. & & & 401 \\
\hline 12 - As pessoas negras são batalhadoras. & & & 370 \\
\hline 31 - O preconceito contra negros existe independentemente da classe social. & & & ,365 \\
\hline 5 - Os negros possuem uma aparência diferente dos demais. & & &, 358 \\
\hline 1 - A beleza das pessoas negras é diferente. & & & ,346 \\
\hline 6 - Os negros de alto poder econômico são discriminados da mesma forma que os negros de classe pobre. & & &, 332 \\
\hline 4 - Os negros são considerados bons parceiros sexuais. & & &, 327 \\
\hline 14 - A imagem dos negros reflete uma pessoa de pele mais escura que as demais. & & & ,301 \\
\hline Eigenvalue & 5,25 & 5,16 & 4,50 \\
\hline Variância Explicada & 11,94 & 11,72 & 10,23 \\
\hline
\end{tabular}


Decidimos então, explorar uma solução fatorial disposta em dois fatores. Os resultados evidenciaram um modelo mais parcimonioso composto preponderantemente por 1) crenças sobre a existência do preconceito racial (Alpha $=0,85)$ e 2$)$ crenças sobre as diferenças étnico-raciais $($ Alpha $=0,79)$, ambos os fatores compos- tos por 12 itens, cada. Itens com carga fatorial inferior a 0,40 foram excluídos, assim como, itens saturados em ambos os fatores (Tabela 3). Foi possível observar que a EAER apresentou uma estrutura psicométrica adequada, com índices de confiabilidade interna considerados satisfatórios (Hair et al., 2005).

Tabela 3. Análise dos Componentes Principais da EAER em 2 fatores

\begin{tabular}{|c|c|c|}
\hline \multirow{2}{*}{ Itens } & \multicolumn{2}{|c|}{ Fatores } \\
\hline & 1 & 2 \\
\hline 40 - Os negros sofrem discriminação. & ,797 & \\
\hline 37 - As pessoas negras sofrem preconceito. & ,783 & \\
\hline 17 - Os negros são pessoas comuns, iguais a mim e aos outros (Invertido). & ,700 & \\
\hline 28 - Os negros sofrem com as injustiças sociais. & ,661 & \\
\hline 41 - A sociedade discrimina as pessoas negras. & ,654 & \\
\hline 36 - Os negros são marginalizados pela sociedade. & 605 & \\
\hline 15 - Os negros são iguais a todos em termos de capacidade (Invertido). &, 595 & \\
\hline 23 - As pessoas negras encontram obstáculos sócio-econômicos e culturais. &, 556 & \\
\hline 38 - O racismo parte tanto dos brancos como dos próprios negros. &, 555 & \\
\hline 27 - A raça negra é uma raça forte e persistente. &, 532 & \\
\hline 12 - As pessoas negras são batalhadoras. & ,459 & \\
\hline 18 - Os negros têm preconceito contra eles mesmos. &, 440 & \\
\hline 20 - O que diferencia os negros dos brancos é o caráter. & & 682 \\
\hline 24 - Os negros se diferenciam dos demais em termos de capacidade. & &, 652 \\
\hline 43 - Por conta da escravidão os negros não atingem sucesso na vida. & & ,618 \\
\hline 9 - Os negros são melhores na dança. & & 617 \\
\hline 29 - O que diferencia os negros dos demais é a capacidade intelectual. & &, 595 \\
\hline 26 - Os negros alcançam melhores resultados no esporte. & &, 587 \\
\hline 30 - A escravidão é a marca central da raça negra. & &, 515 \\
\hline 39 - A humildade é uma característica marcante na personalidade dos negros. & &, 503 \\
\hline 7 - Os negros possuem maior força física quando comparados com os brancos. & &, 500 \\
\hline 22 - A raça negra está ligada à escravidão. & &, 480 \\
\hline 32 - Os negros possuem a sexualidade aguçada. & & 478 \\
\hline 5 - Os negros possuem uma aparência diferente. & & ,457 \\
\hline Média (DP) & $3,92(, 69)$ & $2,61(, 69)$ \\
\hline Eigenvalue & 6,43 & 5,63 \\
\hline Variância Explicada (Total = 27,40) & 14,61 & 12,80 \\
\hline Alpha de Cronbach &, 85 & ,79 \\
\hline
\end{tabular}


Esses resultados demonstram que as atitudes étnico-raciais podem ser estruturadas a partir das dimensões de crenças ético-morais sobre a condição de exclusão e assimetria social vivenciada pelos negros, bem como sobre as crenças que compõem a percepção de diferenças étnico-raciais, assim denominadas por não contemplarem crenças eminentemente de cunho racial, embasadas apenas em diferenças biológicas (Cabecinhas \& Amâncio, 2003).

Os resultados demonstraram também o endosso dos participantes às crenças sobre a existência do preconceito racial (Fator 1) $-\mathrm{M}=3,92(\mathrm{DP}=, 69)$, porém uma relativa rejeição às crenças sobre as diferenças entre negros e bran$\cos ($ Fator 2) $-\mathrm{M}=2,61(\mathrm{DP}=, 69)$. Esse duplo padrão de resposta é frequentemente encontrado na literatura sobre atitudes antinormativas em geral (Moraes \& Camino, 2016; Pereira \& Souza, 2017), e sobre o preconceito e o racismo em particular (Batista et al., 2014; Camino et al., 2014; Lins et al., 2014). Ao passo que se atesta a existência do preconceito racial, também se nega sua existência por meio da recusa de diferenças entre as raças.

Os resultados de uma análise de correlação de $r$ Pearson indicaram independência entre as crenças sobre a existência do preconceito racial e as crenças sobre as diferenças étnico-raciais $(r=-, 078$, N.S.). Pode-se supor que crer na existência do preconceito ou racismo (possivelmente como um fenômeno do outro) não apresente conexão com a percepção de diferença entre negros e brancos. De acordo com Nunes \& Camino (2011), o preconceito racial opera de tal forma mascarada que as pessoas têm aversão a apresentar qualquer vestígio de preconceito, assumindo uma postura condizente com a democracia racial. Para esses autores, essa característica indica a idiossincrasia de como o preconceito é expresso no Brasil, contexto onde a maior parte das pessoas reconhece a presença do racismo, mas não admite responsabilidade nesse processo. Análises que considerem essas particularidades demandam esforços contínuos no sentido de auxiliar no levantamento e avaliação desse padrão de racismo à brasileira.

\section{Considerações finais}

Avaliar atitudes antinormativas não é tarefa fácil. Nesse sentido, a validação de instrumentos elaborados com respaldo teórico consistente tem um papel significativo para o avanço dos conhecimentos sobre essa temática. Com instrumentos adequados é possível conhecer e compreender características importantes dos diferentes níveis e repertórios sobre as relações étnico-raciais. Por meio do conhecimento derivado de estudos como o que apresentamos neste artigo será possível elaborar projetos futuros que visem conhecimentos mais acurados sobre a predição e explicação do preconceito racial. Escalas nacionais elaboradas para mensuração de atitudes raciais ainda são raras. Desta forma, a EAER se apresenta como uma alternativa viável para o estudo das crenças étnico-raciais, podendo ser útil na compreensão do preconceito racial no contexto brasileiro.

A utilização da EAER se faz pertinente tendo em vista ter sido elaborada a partir de um estudo relativamente amplo, com universitários de distintas regiões brasileiras, o que sugere um instrumento composto por itens representativos das principais crenças evocadas no contexto brasileiro sobre as relações raciais. Acresce-se ainda o fato de ser um instrumento breve, de autorrelato e de fácil aplicação.

Para além dos atributos positivos da EAER, é importante destacar algumas fragilidades apontadas nesta primeira versão. A subescala representativa da dimensão de crenças sobre as diferenças étnico-raciais apresenta consistência interna passível de discussão. Apesar de Hair et al. (2005) sustentarem como satisfatórios os índices de confiabilidade interna (Alpha de Cronbach) a partir de 0,60, de acordo com Pasquali (2003), apenas valores próximos de 0,90 são adequados. Portanto, indicamos a realização de novos estudos que se proponham a aprimorar a EAER a fim de avaliar essa fragilidade. Outra fragilidade pode ser relativa à amostra. Por ter utilizado uma amostra homogênea de estudantes universitários de Psicologia, não se pode 
descartar uma possível variabilidade nesta estrutura caso fossem considerados participantes diversificados. Sugere-se, portanto, a ampliação e diversificação da amostra (pelo menos em segmentos universitários variados) como suficiente meio de solucionar essa lacuna. Estudos futuros podem considerar também, por meio da aplicação conjunta de instrumentos correlatos, avaliar a validade concorrente, assim como, a validade discriminante, o que possibilitará ampliar o escopo de evidências de validade da EAER.

\section{Referências}

Alba, M. (2004). El método ALCESTE y su aplicación al estudio de las representaciones sociales del espacio urbano: El caso de la ciudad de México. Peer reviewed online journal, 13, 1-20. https://doi.org/10.24275/uami.9p290936c

Allport, G.W. (1954). The nature of prejudice. Cambridge: Addison-Wesley.

Allport, G.W. (1962). La naturaleza dek prejuicio. Argentina: UEDEBA.

Batista, J. R. M., Leite, E. L., Torres, A. R. R., \& Camino, L. (2014). Negros e nordestinos: similaridades nos estereótipos raciais e regionais. Revista Psicologia Política, 14(30), 325-345.

Cabecinhas, R. \& Amâncio, L. (2003). Naturalização da diferença: representações sobre raça e grupo étnico. Comunicação apresentada na III Jornada Internacional sobre representações sociais. Rio de Janeiro. https://doi. org/10.17771/pucrio.acad.16772

Cabecinhas, R. (2004). Processos cognitivos, cultura e estereótipos sociais. Actas do II Congresso Ibérico de Ciências da Comunicação, Universidade da Beira Interior, Covilhã, 21-24.

Camino, L. Da Silva, P. \& Machado, A. O. (2004). As novas formas de expressão do preconceito racial no Brasil: estudos exploratórios. In M. E. O. Lima \& M. E. Pereira (Orgs.), Estereótipos, preconceito e discriminação: perspectivas teóricas e metodológicas (pp. 119-137). Salvador, BA: EDUFBA. https://doi.org/10.1590/s1413$294 \times 2004000300002$
Camino, L., Gouveia, L., Maia, L. M., Magalhães Ávila Paz, M., \& Laureano, M. (2013). Repertórios discursivos contemporâneos sobre as desigualdades raciais no Brasil. Um estudo com estudantes paraibanos de pós-graduação. Psicologia \& Sociedade, 25(1), 113-122. https://doi. org/10.1590/s0102-71822013000100013

Camino, L., Leite Tavares, T., Rosas Torres, A. R., Álvaro, J. L., \& Garrido, A. (2014). Repertórios discursivos de estudantes universitários sobre cotas raciais nas universidades públicas brasileiras. Psicologia \& Sociedade, 26, 117-128. https://doi.org/10.1590/s0102-71822014000500013

Costa-Lopes, R., Vala, J., Pereira, C. \& Aguiar, P. (2008). A construção social das diferenças nas relações entre grupos sociais. In M. V. Cabral et al. (Eds.), Itinerários: A Investigação nos 25 Anos do ICS (pp. 769-790). Lisbon: Imprensa de Ciências Sociais.

Damásio, B. F. (2012). Uso da análise fatorial exploratória em psicologia. Avaliação psicológica, 11(2), 213-228.

Dancey, C. P., \& Reidy, J. (2013). Estatística sem matemática para psicologia. Penso Editora. Porto Alegre, Brasil.

Devine, P. G. (1989). Stereotypes and prejudice: Their automatic and controlled components. Journal of personality and social psychology, 56, 5-18. https://doi. org/10.1037//0022-3514.56.1.5

Fattore, G. L., Teles, C. A., Santos, D. N. D., Santos, L. M., Reichenheim, M. E., \& Barreto, M. L. (2016). Validade de constructo da escala Experiences of Discrimination em uma população brasileira. Cadernos de Saúde Pública, 32, 1-14. https://doi.org/10.1590/0102-311x00102415

Field, A. (2009). Descobrindo a estatística usando o SPSS-2. Porto Alegre: Artmed.

Guimarães, A. S. A. (2016). Formações nacionais de classe e raça. Tempo Social, 28(2), 161-182. https://doi. org/10.11606/0103-2070.ts.2016.109752

Hair, J. F., Anderson, R. E., Tatham, R. L., Black, W. C. (2005). Análise multivariada de dados. 5. ed. Porto Alegre, RS: Bookman.

Katz, I., Wackenhut, J., \& Hass, R.G. (1986). Racial ambivalence, value duality, and behavior. In J. F. Dovidio \& S. L. Gaertner (Orgs.), Prejudice, discrimination, and racism (pp. 35-59). Nova York, NY: Academic.

Kite, M. E., \& Whitley Jr, B. E. (2016). Psychology of prejudice and discrimination. New York: Psychology Press. 
Lai, C. K., Marini, M., Lehr, S. A., Cerruti, C., Shin, J. E. L., Joy-Gaba, J. A., ... \& Frazier, R. S. (2014). Reducing implicit racial preferences: I. A comparative investigation of 17 interventions. Journal of Experimental Psychology: General, 143(4), 1-68. https:// doi.org/10.1037/a0036769

Leyens, J. P., \& Vala, J. (2016). "Back to the Future:" Ideological Dimensions of Intergroup Relations. In The Social Developmental Construction of Violence and Intergroup Conflict (pp. 85-104). Cham: Springer International Publishing. https://doi.org/10.1007/9783-319-42727-0 4

Lima, M. E., Machado, C., Ávila, J., Lima, C. \& Vala, J. (2006). Normas Sociais e Preconceito: O Impacto da Igualdade e da Competição no Preconceito Automático Contra os Negros. Psicologia: reflexão e crítica, 19(2), 309-319. https://doi.org/10.1590/s0102$\underline{79722006000200018}$

Lima, M. E. O. (2003). Normas sociais e racismo: efeitos do individualismo meritocrático e do igualitarismo na infra-humanização dos negros. (Tese de doutorado Instituto Superior de Ciências do Trabalho e da Empresa, Lisboa. https://doi.org/10.33167/2184-0644. cpp2016.viin1/pp.51-74

Lima, M. E. O. \& Vala, J. (2004). As novas formas de expressão do preconceito e do racismo. Estudos de psicologia, 9(3), 401-411. https://doi.org/10.1590/s1413294x2004000300002

Lins, S., Lima-Nunes, A., \& Camino, L. (2014). O papel dos valores sociais e variáveis psicossociais no preconceito racial brasileiro. Psicologia \& Sociedade, 26(1). https://doi.org/10.1590/s0102-71822014000100011

Lupker, S. J., Perea, M., \& Nakayama, M. (2015). Noncognate translation priming effects in the same-different task: evidence for the impact of "higher level" information. Language, Cognition and Neuroscience, 30(7), 781-795. https://doi.org/10.1080/23273798.2015. $\underline{1015430}$

Máximo, T. A. C. D. O., Larrain, L. F. C. R., Nunes, A. V. D. L., \& Lins, S. L. B. (2012). Processos de identidade social e exclusão racial na infância da solidão. Psicologia em Revista, 18(3), 507-526. https://doi. org/10.5752/p.1678-9563.2012v18n3p507
McConahay, J. B. (1986). Modern racism, ambivalence, and the modern racism scale. In J. F. Dovidio \& S. L. Gaertner (Eds.), Prejudice, discrimination and racism: theory and research (pp. 61-89). New York, NY: Academic Press

Moraes, R., \& Camino, L. (2016). Same-Sex Relationships and Law: A Study on Arguments Used by STF's Ministers When Recognizing Same-Sex Unions in Brazil. Revista Direito GV, 12(3), 648-666. doi: 10.1590/2317-6172201627

Nascimento, A. R. A. \& Menandro, P. R. M. (2006). Análise lexical e análise de conteúdo: Uma proposta de utilização conjugada. Estudos e pesquisas em psicologia, 2, 72-88.

Nicolau, A. C. A., \& Müller, R. F. (2015). O racismo cordial e autoimagem: um estudo sobre os efeitos na adolescência de jovens negras na baixada fluminense/ RJ. Conexões PSI, 3(1), 1-22.

Nunes, A. V., \& Camino, L. (2011). Atitude Políticoideológica e Inserção Social: Fatores Psicossociais do Preconceito Racial?. Psicologia \& Sociedade, 23(1). https://doi.org/10.1590/s0102-71822011000100015

Olson, M. A. \& Fazio, R. H. (2006). Reducing Automatically Activated Racial Prejudice Through Implicit Evaluative Conditioning. University of Tennessee, 32(4), 421-433. https://doi.org/10.1177/0146167205284004

Olson, M. A. (2009). Measures of prejudice. In T. D. Nelson (Ed.), Handbook of prejudice, stereotyping, and discrimination (pp. 367-404). New York, NY: Taylor $\&$ Francis Group.

Oswald, F. L., Mitchell, G., Blanton, H., Jaccard, J., \& Tetlock, P. E. (2013). Predicting ethnic and racial discrimination: A meta-analysis of IAT criterion studies. Journal of personality and social psychology, 105(2), 171-192. https://doi.org/10.1037/a0032734

Pacheco, L. C. (2015). Racismo cordial-manifestação da discriminação racial à brasileira domínio público e o privado. Psicologia, 2(1).

Pasquali L. (2003) Psicometria: teoria dos testes na psicologia e na educação. Rio de Janeiro, RJ: Editora Vozes. 
Pereira, C., Vala, J. \& Leyens, J. P. (2009). From infra-humanization to discrimination: The mediation of symbolic threat needs egalitarian norms. Journal of experimental social psychology, 45, 336-344. https:// doi.org/10.1016/j.jesp.2008.10.010

Pereira, C. R., \& Souza, L. (2017). Fatores Legitimadores da Discriminação: Uma Revisão Teórica. Psicologia: Teoria e Pesquisa, 32(2). https://doi.org/10.1590/ $\underline{0102-3772 \mathrm{e} 322222}$

Pettigrew, T. F. \& Meertens, R. W. (1995). Subtle and blatant prejudice in western Europe. European journal of social psychology, 25, 57-75. https://doi.org/10.1002/ ejsp.2420250106

Pombo-de-Barros, C. F. (2011). Análise textual com o Programa ALCEST: uma aplicação em pesquisa de representações sociais no campo da política. In Mattos, R. A. \& Baptista, T. W. F., Caminhos para análise das políticas de saúde pp. 275-278). Disponível em: http://www.ims.uerj.br/ccaps/wp-content/uploads/2011/10/LivroCompleto-versao-online.pdf $\triangleq \mathrm{http} / / \mathrm{www} \cdot \mathrm{ims} . u e r j . \mathrm{br} / \mathrm{ccaps} / \mathrm{wp}$-content/uploads/2011/10/LivroCompleto-versao-online.pdf. https:// doi.org/10.18310/9788566659399

Santos, W. S., Gouveia, V. V., Navas, M. S., Pimentel, C. E., \& Gusmão, E. É. S. (2006). Escala de racismo moderno: Adaptação ao contexto brasileiro. Psicologia em estudo, 11, 637-645. https://doi.org/10.1590/S1413$\underline{73722006000300020}$

Sears D. O. (1988). Symbolic racism. In P. A. Katz \& D. A. Taylor (Eds.), Eliminating Racism: Profiles in Controversy, Perspectives in social psychology (pp. 5384). New York, NY: Plenum. https://doi.org/10.1007/978$\underline{1-4899-0818-6 \quad 4}$

Turra, C. \& Venturi, G. (1995). Racismo cordial: a mais completa análise de preconceito de cor no Brasil. São Paulo, SP: Ática.

Recebido em: 24.09.2017.

Aceito em: 24.08.2018.

Publicado em: $\mathrm{xx} / \mathrm{x} / \mathrm{xxxx}$

\section{Endereço para correspondência:}

Sheyla C. S. Fernandes
Av. Silvio Carlos Viana, 2343, Ap. 503. Ponta Verde, Maceió - Alagoas. CEP 57035-160.

Telefone: (82) 99936-4300; E-mail: sheyla.fernandes@ip.ufal.br). 